ENTREVISTAS

http://dx.doi.org/10.1590/2176-457344156

\title{
Thomas Fink entrevista Lakshmi Bandlamudi: Difference, Dialogue and Development: a Bakhtinian World
}

Tradução de Anselmo Lima*

e Miriam Ruffini**

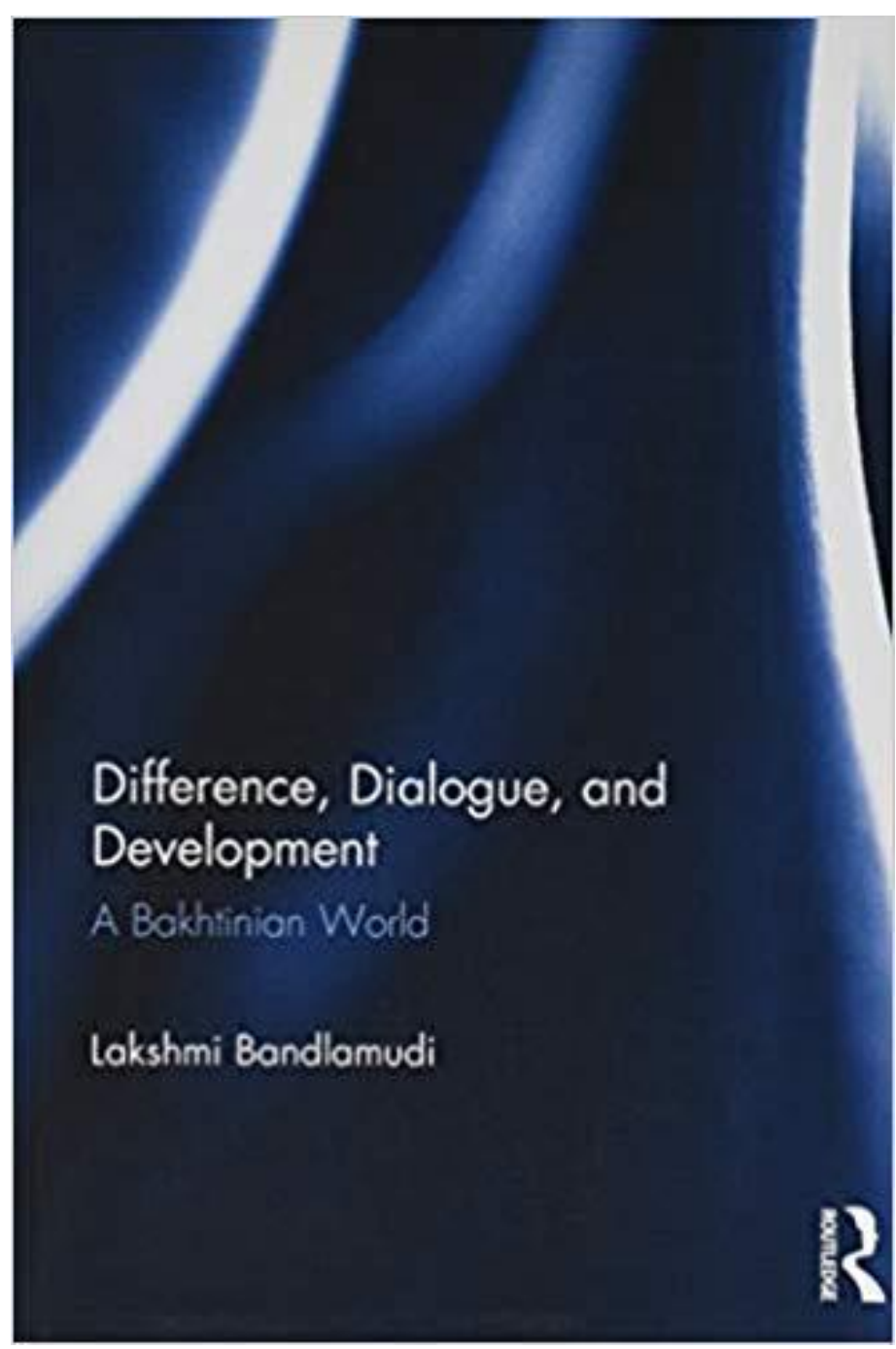

\footnotetext{
* Universidade Tecnológica Federal do Paraná - UTFPR, Campus Pato Branco, Departamento de Letras, Pato Branco, Paraná, Brasil; https://orcid.org/0000-0003-1427-2165; selmolima@ @otmail.com

** Universidade Tecnológica Federal do Paraná - UTFPR, Campus Pato Branco, Departamento e Coordenação de Letras - DALET/COLET, Pato Branco, Paraná, Brasil; https://orcid.org/0000-0002-32222519; mruffini95@gmail.com
} 


\section{Apresentação}

Anselmo Lima***

Em 2014, em função de determinado interesse de pesquisa na ocasião de um estágio de pós-doutorado nos Estados Unidos, financiado pela CAPES-FULBRIGHT, eu me esforçava por encontrar, entre os pesquisadores bakhtinianos que eu poderia acessar naquele país, alguém que discutisse as teorias bakhtinianas em diálogo ou articulação com teorias vigotskianas, em especial com aquelas que se podem ler em uma obra específica de Vigotski: Psicologia da arte. O fato é que não estava sendo muito fácil identificar alguém precisamente com esse perfil. Mas qual não foi minha surpresa quando, já tendo de alguma forma desistido da empreitada, ao examinar anais de eventos bakhtinianos ocorridos mundo afora, me deparei com o nome de uma pesquisadora indiana radicada nos Estados Unidos: Lakshmi Bandlamudi. Ela era precisamente quem eu procurava.

Após ler seu trabalho, decidi escrever para ela um e-mail. E a resposta veio rápida e acolhedora. Entendemo-nos tão bem nas correspondências que decidimos nos encontrar para almoçar e conversar pessoalmente em Nova Iorque, cidade onde ela reside. De lá para cá, mantemos o contato e a colaboração acadêmico-científica. E a forma diferenciada como Lakshmi Bandlamudi lê e interpreta os escritos de Bakhtin e do Círculo tem sido uma contribuição importante para o desenvolvimento do modo como eu mesmo os venho lendo e interpretando. Considerei, então, que o público brasileiro leitor de Bakhtin (e também de Vigotski) poderia talvez, assim como eu, se beneficiar da contribuição que a autora indiana-estadunidense tem a dar. É por esse motivo que, com o apoio e participação fundamental e indispensável da colega Mirian Ruffini, providenciamos a tradução da presente entrevista para a língua portuguesa e a submetemos para publicação na Bakhtiniana.

Lakshmi Bandlamudi é professora de Psicologia na LaGuardia Community College, City University of New York. É autora de Dialogics of Self, The Mahabharata

\footnotetext{
*** Universidade Tecnológica Federal do Paraná - UTFPR, Campus Pato Branco, Departamento de Letras, Pato Branco, Paraná, Brasil; https://orcid.org/0000-0003-1427-2165; selmolima@ hotmail.com
}

Bakhtiniana, São Paulo, 15 (1): 180-197, jan./março 2020. 
and Culture: The History of Understanding and Understanding of History ${ }^{1}$, e de vários artigos com foco na consciência dialógica. A propósito do livro que constitui o objeto da presente entrevista ${ }^{2}$, originalmente publicado em 2016, e também a respeito de sua autora, comenta ninguém menos que Michael Holquist, professor emérito da Universidade de Yale, na própria obra:

[...] em todo um oceano de trabalhos bakhtinianos, eis aí uma nova voz. Lakshmi Bandlamudi une em uma única leitura trabalhos dispersos que Bakhtin escreveu ao longo de toda a sua vida e adiciona 'Desenvolvimento' aos já costumeiros 'D's' (de Diálogo e Diferença). Ao fazer isso, acrescenta uma outra dimensão à heteronomia chamada 'Bakhtin' (p.ii) .

A “voz" de Lakshmi é, de fato, uma voz original. E isso pode agora ser conferido pelos leitores brasileiros, bakhtinianos ou não, vigotskianos ou não, em língua portuguesa, ao menos na presente entrevista, que aborda inclusive temas políticos tão atuais e delicados no cenário estadunidense, os quais fazem muito sentido, por analogia, no próprio contexto do Brasil e do mundo de hoje. Quanto ao livro da autora, deverá, por enquanto, ser acessado e lido em língua inglesa. Mas, para que dele se possa ter uma ideia complementar à da entrevista, seguem, de modo breve, suas linhas gerais.

A obra está organizada em sete capítulos, cujos títulos dão uma boa noção de seu conteúdo: capítulo 1, "Introdução: Diálogo = Desenvolvimento"; capítulo 2, "O romance e o herói: a narrativa desenvolvimental e o sujeito em desenvolvimento"; capítulo 3 , "Vida criativa e visão estética: cultivando sensibilidades mais refinadas"; capítulo 4, “Carnavalização da consciência: um catalisador para o desenvolvimento"; capítulo 5, “Autorando o self - respondendo ao outro: necessidades epistemológicas e obrigações éticas"; capítulo 6, "Método dialógico para as Ciências Humanas"; e, finalmente, capítulo 7: "Diferenças como ânsia pelo poder e liberdade de escolha".

\footnotetext{
${ }^{1}$ BANDLAMUDI, L. Dialogics of Self, The Mahabharata and Culture: The History of Understanding and Understanding of History. UK: Anthem Press, 2010.

${ }^{2}$ BANDLAMUDI, Lakshmi. Difference, Dialogue, and Development: a Bakhtinian World. New York: Routledge, 2016.

${ }^{3}$ No original: "In an ocean of Bakhtiniana, this is a fresh voice. Lakshmi Bandlamudi brings together the disparate works Bakhtin wrote over a long lifetime in a reading that adds 'Development' to the usual 'Ds' (Dialogue, Difference) in Bakhtin studies. In so doing, she adds another dimension to the heteronomy called 'Bakhtin'."
} 
Por fim, resta dar uma palavra sobre o ilustre entrevistador. Trata-se de Thomas Fink, colega de trabalho de Lakshmi. É poeta, crítico literário e professor de inglês na LaGuardia Community College, City University of New York. É autor de nove livros sobre poesia, dois livros de crítica e de uma antologia literária. Além disso, coeditou duas antologias críticas e apareceu em 2007 na edição The Best American Poetry, de Scribner. É também o responsável pelo site "Dichtung Yammer", no qual publica entrevistas com diversos autores, especialmente nas áreas de poesia e outras produções culturais que tenham uma dimensão poética. A forma como ele conduz a entrevista com Lakshmi Bandlamudi, sem dúvida alguma, resulta em um diálogo que o leitor interessado em questões da atualidade à luz do pensamento bakhtiniano não se arrependerá de conferir e acompanhar atentamente até o fim.

\section{Entrevista $^{4}$}

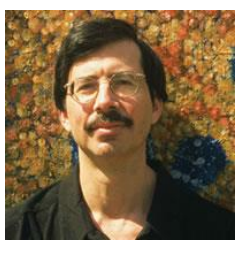

Thomas Fink: Em Diferença, diálogo, e desenvolvimento, você dá continuidade ao corpo já bastante significativo de seu trabalho a respeito da filosofia do dialogismo de Mikhail Bakhtin e o aplica à área da psicologia do desenvolvimento. No quarto capítulo, você argumenta que a noção de carnavalização de Bakhtin fornece um "catalisador para o desenvolvimento" da "consciência... em todas as suas múltiplas faces", especialmente em seu destaque da "nossa natureza maliciosa, desafiadora e irrepreensível". Você afirma que a "consciência carnavalizada" nos ajuda a superar o medo, o desespero, e a estagnação, os quais são todos fortes possibilidades, à medida que as pessoas de centro-esquerda preveem a ascensão de Donald Trump. Além das vozes distintas no espaço dialógico da carnavalização, que são realizadas dentro de um “cronotopo" (tempo-espaço) historicamente específico, uma paródia de dogmas dominantes, por meio das estratégias que Bakhtin denomina “discurso bivocal”, é uma característica proeminente. Mais adiante no capítulo, você também discute as formas problemáticas da carnavalização - e chegaremos a isso em minha próxima pergunta - mas primeiramente eu gostaria que você identificasse um ou dois fenômenos positivos sobre o desenvolvimento do carnavalesco

\footnotetext{
4 Entrevista original publicada em: https://dichtungyammer.wordpress.com/2017/03/19/exchange-onlakshmi-bandlamudis-difference-dialogue-and-development-a-bakhtinian-world-routledge-2015/
} 
na cultura estética contemporânea, e então nos relatasse por que esse tipo de atividade carnavalesca exerce um impacto positivo na sociedade global.

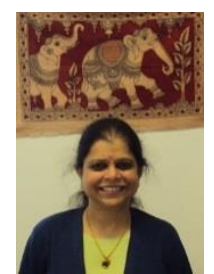

Lakshmi Bandlamudi: O Carnaval já foi uma arma poderosa para os antigos povos, destinado como uma ferramenta de correção quando as sociedades se distanciavam muito da verdade. Esse arsenal antigo conseguiu de forma eficiente desvendar as camadas que encobriam a hipocrisia, destruir as formas hierárquicas opressivas e atacar a falsidade. Dessa forma, ele é muito fiel à verdade. Bakhtin observa que a força filosófica do riso tem enfraquecido acentuadamente à medida que nós ingressamos na era moderna. Diferentemente do período anterior, quando a comédia e a tragédia coexistiam, nossa era contemporânea as separou em entidades polarizadas e, consequentemente, o riso carnavalesco que celebrava as ambiguidades e indeterminações perdeu seu ardor. Como resultado, quando você me pede para identificar um "fenômeno positivo a respeito do desenvolvimento do carnavalesco na cultura estética contemporânea", minha primeira resposta a isso é, eu lamento muito essa perda, e faço um alto clamor, a fim de reivindicar a arma que costumava ser uma companheira próxima à verdade. É importante lembrar que certos aspectos da realidade estão acessíveis apenas ao riso.

As sociedades e mentes abertas não têm receio do riso porque elas se comprometem a encarar as verdades inconvenientes - as amargas verdades - para que elas mudem a realidade ativamente e a transformem. Em nossa vida cultural, parece que entramos em um mundo perigoso da pós-verdade e a ascensão de Donald Trump é uma manifestação desse fenômeno. O cronotopo carnavalesco está sempre em uma missão em "busca da realidade" e de "afirmação da verdade" e então o 'sábio louco' apresenta um mundo invertido para mostrar que estamos considerando erroneamente a hipocrisia como santidade. O mundo 'pós-verdade', por outro lado, demonstra total desconsideração até por fatos visíveis e verificáveis e, como consequência, qualquer consideração pela verdade parece implausível. Diversamente ao "mundo de mentiras" que sabe da verdade e a encobre com mentiras, o mundo pós-verdade distorce a verdade livremente em uma abordagem em que "tudo vale". Fugir da verdade é apenas um ato de timidez, mas distorcê-la é perverso, psicótico e diabólico e nessa atmosfera há pouco espaço para o carnaval. A comédia e a sátira são as primeiras fatalidades à medida que as sociedades se 
movem rumo a dogmas e autoritarismo. Os cartuns políticos costumavam ser um componente comum nos jornais e na atualidade eles praticamente não existem.

Entretanto, isso não significa que o cenário seja sombrio. A sátira política e os shows de comédia stand-up ainda criam, efetivamente, o espaço carnavalesco. Entretanto, esse gênero alcança apenas o público já convertido e receptivo. O espaço e o tempo do carnaval devem ser muito mais penetrantes na sociedade para que haja um impacto positivo. É também importante ter em mente que o cronotopo carnavalesco permanece na margem e, consequentemente, é capaz de estar vigilante em relação ao funcionamento das convenções culturais, e quando as práticas normativas atingem o seu pico e perdem seu objetivo original, o carnaval as expõe e as corrige. Dessa forma, o carnaval não é o inimigo dos códigos de conduta culturais. O que presenciamos na atualidade é a normalização e centralização do carnaval - uma forma bruta que somente retém a linguagem provocante e o anticonvencionalismo e a anarquia gratuita, e não aquela anarquia intencional a que o carnaval se dedica e, como consequência, o carnaval perdeu o seu significado e objetivo.

Fink: Eu concordo que muitos humoristas que fazem sátira e stand-up sobre política "criam o espaço carnavalesco verdadeiro", quando penso em comediantes como Sarah Silverman, que foi criticada tanto pela direita como pela esquerda, que parece um carnaval por si só, e em como figuras e temas reacionários e progressistas circulam livremente nos números de comédia que ela apresenta de forma impassível, enquanto que Margaret Cho e Louis C.K. parecem mais claramente situados em uma agenda progressista, mas obtêm esse efeito de diferentes maneiras. Então, sim, o carnavalesco revela "verdades inconvenientes", mas eu pensaria que a (sua) função é de circular os produtos oriundos de discursos opostos, incluindo aqueles que podem ser considerados desconfortavelmente falsos ou "pós-verdade", ou até mesmo horríveis. Por exemplo, e eu posso estar errado sobre isso, eu entendo Silverman tanto como uma paródia performática como discurso bivocal e não tomo como literal quando ela faz um estereótipo de personalidades de cultura afro-americana, e eu compreendo que Cho, que é tão positiva com declarações públicas de peso a respeito de homens gays, também utiliza a paródia como discurso bivocal quando ela apresenta as imagens estereotipadas de homens gays. Louis C. K. às vezes parece feminista e às vezes machista, mas, naturalmente os comediantes afro- 
americanos como Chris Rock e Chris Tucker frequentemente usam versões extremamente complexas de discurso bivocal.

Eu estou errado em pensar a respeito do "carnavalesco" dessa forma? E, para retornar à sua assertiva de que "este gênero atinge somente o público já convertido e receptivo", o que os humoristas que fazem sátira e stand-up sobre política precisariam fazer para ampliar o público de sua crítica cultural?

Bandlamudi: Sua interpretação é muito válida e, como você corretamente aponta, "a função é fazer circular os produtos oriundos de discursos concorrentes...”. A cultura é sempre heterogênea com pontos de vista divergentes e ideologias concorrentes e toda escola de pensamento é suscetível aos seus extremos e aos seus vazios. Como resultado, os dogmas aparecem de várias formas - existe o dogma da direita e o dogma da esquerda também - e o espaço do carnaval não poupa nenhum grupo e é isso que percebemos na comédia da Sarah Silverman e de Bill Maher e de outros humoristas.

Quando os grupos abraçam um ideal e se conduzem na direção oposta, a hipocrisia se torna obviamente visível, e quando as ideologias que eles promovem não condizem com a realidade, os ideais pretendidos se tornam obsoletos e corrompidos, e quando os métodos para atingir os seus ideais não conseguem conduzi-los ao seu objetivo, então é um lapso de inteligência e, em geral, nesses casos, as risadas carnavalescas e a linguagem apimentada se tornam medidas corretivas muito necessárias. Ele (o carnavalesco) zomba da falsa piedade e a alerta contra o consumo de ideias e ideais ultrapassados e indica a direção errada dos seus métodos. Curiosamente, até mesmo os métodos que produzem a sátira e a comédia são igualmente variados. Alguns recorrem à encenação do "tolo ingênuo" (de fato, o tolo sábio) a fim de fazer as perguntas certas. Jon Stewart sempre utilizava essa tática. Na realidade, muitos bons escritores usam uma criança inocente, um bêbado ou um louco como recursos literários eficientes para apresentar questionamentos inconvenientes. Outro método consiste em simplesmente ampliar e aumentar a realidade para mostrar os absurdos e a personagem de Stephen Colbert em seu show anterior fazia isso brilhantemente. O ventríloquo Jeff Dunham combina ambas as estratégias - ele se faz de bobo e o seu boneco fala algo absurdo.

Talvez o lema do espaço carnavalesco seja "espaço para todos" e também "ninguém é poupado" e é dessa forma que ele (o carnavalesco) mantém vivos e ativos os discursos 
antagônicos. Uma vez que o espaço do carnaval é aberto a todos e todos são participantes iguais no espetáculo, não podemos depender exclusivamente dos satiristas e comediantes de stand-up para nos revelar o absurdo. Isso precisa ser uma parte integral da sociedade. Estamos presos a muita falsa seriedade e ultrassensibilidade (todo mundo se ofende com tudo) e nesse tipo de clima, as discussões francas se tornam praticamente impossíveis. Para que o riso tenha sua força e poder, a sociedade precisa ser sensível à verdade interior e à liberdade interna e é por isso que a máscara de carnaval que o palhaço usa serve somente para retirar as camadas das máscaras psicológicas que nós usamos. Enquanto a exterioridade é enfatizada, nós encenamos um espetáculo e continuamos a viver na falsidade de todos os tipos. Quando nos tornamos conscientes a respeito da ironia e da impossibilidade de reconciliação das entidades na nossa vida cultural, então o riso se torna uma força libertadora - liberando-nos, não do mundo sombrio, mas para o mundo desorganizado - e então, mesmo que as coisas permaneçam as mesmas, você pode se sentir triunfante com uma boa risada.

Fink: No Capítulo 5, A autoria do self - A resposta ao Outro, você observa que "os encontros com os diversos outros e as culturas estrangeiras somente abrem possibilidades para a compreensão criativa, mas o indivíduo deve responder dialogicamente para que isso ocorra" (p.103). Você alerta a respeito da ilusão de que "uma simples reunião de pontos de vista e de culturas diversas" equivale à "dialogicidade, porque cada um pode permanecer intocado pelo outro, ou as identidades podem se tornar amorfas e as culturas fragmentadas". Há tantos exemplos na política externa ao longo da história dos Estados Unidos que exemplificam que nossa liderança "permanece intocada pelo outro" enquanto supomos interpretá-la; o Vietnam e o Iraque foram talvez os casos mais marcantes durante toda minha vida. Mas eu me interesso pelo que você considera "identidades que se tornam amorfas" por meio do diálogo falso e se existem alguns exemplos que esclareceriam isso. E também qual é a maior diferença entre aprender a partir do "outro" e ter sua própria cultura "fragmentada"?

Bandlamudi: No mundo multicultural em que vivemos, no qual há encontros frequentes com outras culturas e fés, há amplas oportunidades para a compreensão dialógica do self, da cultura e da história. A confrontação ou os encontros face a face entre o self e o outro 
e entre múltiplos textos e períodos de tempo são necessários, pois muitos aspectos deles são invisíveis para nós quando são vistos como entidades isoladas. O self precisa do outro como um espelho; um texto precisa de outros textos para mostrar suas inúmeras possibilidades semânticas, e o passado e o presente precisam um do outro para se compreenderem. Agora, a questão é se a justaposição é mecânica ou se a metamorfose foi alcançada.

Quando os aspectos do self e da cultura que estão escondidos se tornam visíveis nos encontros com os outros, isso é acompanhado de certa ansiedade, o que é compreensível e muito frequentemente os indivíduos respondem a essa ansiedade criando "passados românticos" e "pátrias imaginárias", ou eles se desenraizam completamente do seu passado cultural. Em ambos os casos o self perde sua estrutura e forma e não consegue tomar posse das ações e pensamentos em uma cultura mutável. Tome, por exemplo, os sentimentos anti-imigratórios por toda a Europa e infelizmente agora nos Estados Unidos - os residentes de longa data desejam retornar às suas noções presumidas de "nativismo" e "filho original da terra", e os grupos de imigrantes, em sua incapacidade ou falta de vontade de se ajustarem ao novo mundo, sonham com lares imaginários e passados românticos e essas duas tendências levam ao extremismo e as identidades se tornam instáveis. Existe praticamente uma cisão entre o self e as realidades dos fundamentos da cultura e isso não deixa praticamente espaço para a compreensão criativa da cultura e da história. Navegar através de um mundo multicultural é mais do que vestir trajes para uma festa a fantasia. Quando o self está inconsciente das mudanças dinâmicas que ocorrem na cultura, a identidade se torna amorfa, fraca e rígida. Com respeito a essa última questão, a incapacidade de aprender a partir dos outros gera uma nação dividida ou uma cultura fragmentada e é isso que estamos presenciando na atualidade. É uma forma de tribalismo primitivo em uma vila global e nenhum grupo deseja ouvir a realidade vivida pelo outro. Aprender por meio dos outros ou ouvir aos outros realmente mantêm uma nação/cultura unidas para atingir o ideal da "Unidade na Diversidade".

Fink: Eu penso que o seu diagnóstico sobre o problema atual a respeito das perspectivas sobre a imigração seja extremamente convincente. Na poesia de A. K. Ramanujan, um acadêmico proeminente que passou quase metade da vida na Índia, seu país de origem, e um pouco mais da metade como professor na Universidade de Chicago, podemos ver um 
exemplo curioso de "aprender por meio de" e "ouvir os outros" - isto é, o dialogismo. Em sua obra, escrita em inglês (para aqueles que possam perguntar), há esforços frequentes de se abrir para a multiplicidade do sofrimento no mundo, também sabendo como é difícil: "Como se pode escrever a respeito da Bósnia, de Biafra, Bangladesh, tomando apenas as atrocidades que começam com B, alfabetizar as crueldades, comendo caquis e dormindo em segurança nos braços da pessoa amada, a lua úmida na janela com pinázio?"5.

Ainda assim, esse dialogismo, às vezes desorientador, começa por estar situado na tentativa da representação do self, como no poema Autorretrato (Self-Portrait): "Eu me pareço com todo mundo/ exceto comigo mesmo", e o interlocutor encontra "nas vitrines,... o retrato de um estranho,/ data desconhecida,/ frequentemente assinado em

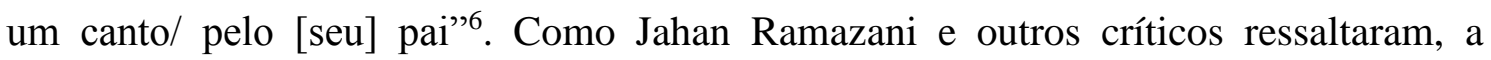
perspectiva bicultural de Ramanujan - nos termos de Ramazani, a necessidade de "traduzir" entre culturas para quem era, na realidade, famoso por suas traduções influencia imensamente sua poesia e o gesto autodesfamilizarizador no trecho acima, uma vez que ele se enxergou composto de tanta alteridade. No poema Um relatório, ele cataloga as mortes e a recontextualização ("renascimento") de inúmeros indivíduos como fenômenos culturais, e termina, praticamente atordoado com um senso de tal heterogeneidade, com a questão: "Ainda o que posso fazer, o que farei, Ó deus da morte e das doces águas abaixo ou ao lado do sal e dos detritos, o que posso fazer além de dormir, trabalhar no amor e trabalhar, errar, dormir novamente recusando, a menos que eu desmorone, sonhar com uma casa azul de Mysore em Chicago?"7.

Pode-se explorar porque ele pensa que ele “desmoronaria” por sonhar com (ou até mesmo tendo construído) "uma casa azul de Mysore em Chicago" (RAMANUJAN, A. K., Op.cit, p.249) e, mais significativamente, o que a imagem final desse poema tem a dizer sobre os

\footnotetext{
${ }^{5}$ How can one write about Bosnia, Biafra, Bangladesh, just to take only the atrocities that begin with B, alphabetize cruelties, eating persimmons and sleeping safe in the arms of a lover, a wet moon in the mullioned window? (RAMANUJAN, A. K. Collected Poems. New Delhi: Oxford University Press, 1995, p.247).

6 "I resemble everyone/ but myself," and the speaker finds "in shop-windows, ... the portrait of a stranger,/ date unknown,/ often signed in a corner/ by [his] father" (RAMANUJAN, A. K. Collected Poems. New Delhi: Oxford University Press, 1995, p.23).

${ }^{7}$ Yet what can I do, what shall I do, O god of death and sweet waters under or next to the salt and the flotsam, what can I do but sleep, work at love and work, blunder, sleep again refusing, lest I fall asunder, to dream of a blue Mysore house in Chicago? (RAMANUJAN, A. K. Collected Poems. New Delhi: Oxford University Press, 1995, p.249).
} 
empreendimentos dialógicos. Como a poesia de Ramanujan pode ter pontos de contato com a consideração do diálogo e o desenvolvimento em seu livro?

Bandlamudi: A. K. Ramanujan é um pensador muito versátil e suas obras sem dúvida se prestam muito bem à dialogicidade. Oriundo de uma cultura multilíngue e heterocrônica (coexistência de múltiplas temporalidades), ele incorpora o que muitos acadêmicos descreveram como a consciência indiana, uma "consciência da tradução." Quando você vive em uma cultura diferente, que opera em uma variedade de linguagens, os significados devem ser negociados e às vezes os significados são também perdidos na tradução, ou alguns conceitos são simplesmente intraduzíveis e isso mostra os limites da tradução e do tradutor. É com absoluto conhecimento desta limitação que um pensador e poeta com a profundidade de Ramanujan habilmente deixa os seus textos abertos e sugestivos de forma a impulsionar o leitor a um horizonte imaginário, consequentemente convidando o leitor como um parceiro em um diálogo.

Bakhtin observa que quando olhamos nossa imagem no espelho, mesmo na privacidade da nossa casa, observamos como nós nos vemos, juntamente à forma que os outros nos veem e com a nossa resposta à maneira que pensamos que os outros nos veem. Essa fórmula triádica fica evidente em Autorretrato, de A. K. Ramanujan, pois ele reconhece a sua gênese, que é somente uma parte pequena do seu self (a assinatura de seu pai em um canto), mas, maior que isso é o conjunto dos 'outros' no autorretrato, assim afirmando a presença de outros dentro do self e não fora do self, e isso é um componente central do self dialógico.

Em seu poema Bosnia ${ }^{8}$, Ramanujan constrói um diálogo entre as experiências corporais - saborear caquis, a emoção de estar nos braços da pessoa amada e a lua como testemunha da cena agradável (os Contos da Índia ${ }^{9}$ - clássicos e folclóricos - estão cheios de imagens da lua como testemunha, um juiz e um guia na noite escura, e são chamados de Chandamama - Tio Lua...) - e o que a mente atormentada alerta com a grande quantidade de atrocidades que estão acontecendo ao redor do mundo. A mente está alertando que os sentimentos de segurança e êxtase são precários; eles podem ser roubados de você a qualquer momento. $\mathrm{O}$ prazer e a dor coexistem em um diálogo constante.

\footnotetext{
${ }^{8}$ RAMANUJAN, A. K. How Can One Write about Bosnia. In: Collected Poems. New Delhi: Oxford University Press, 1995, p.247.

${ }^{9}$ A autora refere-se às coletâneas diversas disponíveis de contos clássicos e folclóricos da Índia.
} 
Ramanujan escreve o poema Um relatório sobre como os personagens maus (Hitler, Stalin) e nobres (Gandhi, King) nascem e renascem e infelizmente os primeiros aparecem e reaparecem em grande número em um ritmo muito mais rápido que os últimos (algumas gerações chegam até a deixar de ver um personagem nobre durante seu tempo de vida). Consequentemente, na jornada da vida, há muitos desastres - naufrágios - então ele pede ao "Deus da Morte"10 (acredito que ele se refira a Vishnu deitado confortavelmente em uma postura indolente no oceano cósmico quando ele se refere às doces águas por debaixo...) o que ele pode fazer agarrado aos detritos com água salgada em sua boca? Ele não pode fazer as coisas grandiosas que os personagens nobres fizeram, e nem pode ser um espectador passivo das atrocidades e tudo que ele pode fazer é "dormir, trabalhar no amor e trabalhar, errar..."11. Até mesmo o sono se torna um luxo quando você não consegue alcançar as estrelas no céu aberto e também não consegue viver em um mundo injusto. Eu ouço múltiplas vozes quando ele se lamenta, "a menos que eu desmorone, sonhar com uma casa azul de Mysore em Chicago"12 e seu medo de desmoronar se relaciona à nossa discussão anterior sobre identidades amorfas.

Sempre há o medo de aniquilamento à medida que nós percorremos um mundo globalizado - muitos encontros, muitos encontros estranhos, surpresas ocasionais que são agradáveis, e muitas formas de mal... a lista continua - e sob essas circunstâncias, ele pode fugir para o lugar familiar - a casa "azul de Mysore" - para buscar abrigo lá, e isso é o que ele receia e tem pavor porque é um ato de timidez. Ou em outro nível, ele pode sentir a necessidade de revisitar a sua "casa azul de Mysore" mesmo que seja no seu sonho em uma cama em sua casa de Chicago, porque essa é sua âncora, o ponto do qual ele opera neste vasto mundo. Excursionar por seu passado, por seu espaço cultural, confere a ele uma posição no mundo e evita a fragmentação. Seria esclarecedor apresentar brevemente a obra de Ashis Nandy ${ }^{13}$, um teórico cultural eminente na Índia, que escreveu sobre a viagem do self de um vilarejo para a cidade e essa viagem de ida e volta, literal e figurativamente contribui de forma imensa para o pensamento criativo por causa da

\footnotetext{
${ }^{10}$ Yet what can I do, what shall I do, O god of death and sweet waters under or next [...] (RAMANUJAN, A. K. Collected Poems. New Delhi: Oxford University Press, 1995, p.249).

${ }^{11}$ No original: “[...] sleep, work at love and work, blunder, [...]” (RAMANUJAN, A. K. Collected Poems. New Delhi: Oxford University Press, 1995, p.249).

${ }^{12}$ No original: “[...] lest I fall asunder, to dream of a blue Mysore house in Chicago?” (RAMANUJAN, A. K. Collected Poems. New Delhi: Oxford University Press, 1995, p.249).

${ }^{13}$ NANDY, A. An Ambiguous Journey to the City: The Village and Other Odd Ruins of the Self in the Indian Imagination. New Delhi: Oxford University Press, 2006.
} 
dialogicidade entre ambos (evidente nas obras de Ramanujan). Ao passo que uma viagem sem o retorno periódico ou nunca ter feito a viagem em nenhuma das duas direções poderia levar à fragmentação do self visto que não há fatores externos para romper a zona de conforto.

Nandy usa "vilarejo" como uma metáfora para o self interior - vilarejo como idílico, simples, transparente, aconchegante e confortável, onde ninguém é desconhecido - mas o self também precisa vaguear em uma metrópole maior que está sempre mudando, intimidadora e solitária, expondo as pessoas a duras realidades. O movimento de uma para outra está cheio de ambiguidades e conscientização sobre as limitações de uma pessoa. Pode-se ficar perdido em uma metrópole, porque o anonimato é a característica da vida na cidade. Uma viagem inequívoca desde o vilarejo até à cidade desestrutura o indivíduo. Curiosamente, ao mesmo tempo que Bakhtin celebra um mundo aberto, ele salienta que fechamentos rítmicos, momentâneos e periódicos são necessários para que o indivíduo não fique perdido no fluxo cultural para sempre. Ao mesmo tempo, o vilarejo não pode ser romantizado, nem pode ser um abrigo permanente em seu horizonte psicológico para escapar das realidades duras da vida. Este é o perigo do qual Ramanujan parece extremamente consciente e, ainda assim, ele não quer renunciar ao vilarejo (Mysore) ou à cidade (uma cidade global como Chicago); ao invés disso, ele vai e vem e o vilarejo simples e pequeno entra em diálogo com a cidade grande e complicada consequentemente, expandindo seu horizonte psicológico. Ramanujan se move entre espaços culturais, e também entre zonas temporais - o passado remoto e o presente contemporâneo - e estes períodos de tempo estão também em um diálogo contínuo e isso é o que torna suas obras tão maravilhosamente dialógicas e criativas.

Fink: Eu tenho ensinado alguns dos poemas de Ramanujan em várias disciplinas por aproximadamente dez anos, e você me deu muito o que pensar para a próxima vez que eu trabalhar com esses poemas no futuro. Obrigado.

No Capítulo 6, Método dialógico para as Ciências Humanas, você reconhece a primazia do "monologismo, sob certas circunstâncias," pois "não há múltiplos pontos de vista sobre certos tópicos como assédio sexual, escravidão, genocídio, e muitos mais" (p.120). Eu concordo, naturalmente. E, ainda assim, em termos práticos, para reduzir o número de casos de assédio sexual, para tomar um exemplo dessa triste lista, que ocorre em uma 
certa sociedade, por meio de medidas preventivas quais são as estratégias dialógicas necessárias para persuadir, digamos, homens jovens heterossexuais impregnados da ideologia patriarcal a abrirem-se para conceitos feministas e - aqui estou usando os termos da Terapia Racional Emotiva Comportamental de Albert Ellis - contestar suas crenças irracionais e, dessa forma, mudar os aspectos das emoções persistentes e principalmente seu comportamento? Por estratégias dialógicas, penso que eu queira dizer que se deve entrar na ideologia do jovem parceiro dialógico de uma forma que não seja meramente condescendente ou horrorizada, mas que afirme alguma dimensão do seu pensamento e da sua existência. Ou seria ingênuo pensar que o dialogismo deve fazer a diferença?

Bandlamudi: O diálogo é tanto um mediador para o crescimento e o desenvolvimento quanto é um indicador do desenvolvimento. É um método e um ideal e buscamos isso não por ingenuidade, mas com o objetivo e comprometimento de dar ao outro uma oitiva justa, sabendo muito bem que a cortesia oferecida pode não ser correspondida. Os monologistas fanáticos, mesmo aqueles não propensos à violência, não desejam ouvir o outro, e, além disso, têm necessidade de negar o outro para afirmar a si próprios. Consequentemente, aqueles favoráveis ao dialogismo sem dúvida se arriscam bastante quando tentam travar uma conversa com um monologista teimoso - que não hesitará em invadir o seu território (afinal, a abertura é fornecida pelo interlocutor que inicia o diálogo) - e demolir suas palavras e ideias. Os monologistas sempre buscam ou exigem um álibi para suas ações e pensamentos. Eles se cercam de "homens do sim" - que farão os seus elogios. Infelizmente, estamos presenciando exatamente isso no nosso governo atual. Podemos tentar entrar na ideologia do outro, se for uma questão de diferenças filosóficas ou visões de mundo ou diferentes soluções para um mesmo problema (tenho lido cartas trocadas por John Adams e Thomas Jefferson, que eram o polo norte e o polo sul do movimento revolucionário, mas que eram capazes de entrar em diálogo), mas não podemos e não devemos entrar na ideologia de um megalomaníaco, ou de uma pessoa propensa à violência ou um fanático. Uma das partes mais frustrantes de nossos discursos atuais sobre questões políticas é elaborar uma falsa equivalência de forma pouco problemática e injustificada. Por exemplo, os grupos que questionaram a legitimidade da Presidência de Obama em grande parte estavam dando vazão ao seu preconceito racial, enquanto os 
grupos que resistem a Trump ficam horrorizados pelos seus comentários ofensivos sobre praticamente todos os grupos. Eles não estão no mesmo nível. Entretanto, os indivíduos que fecham os olhos para suas visões sexistas e racistas e, ainda assim, estão de certa forma abertos à mudança podem muito bem ser trazidos ao espaço dialógico para promover uma mudança lenta e estável, e você está certo; precisamos nos engajar em táticas persuasivas sem o repúdio extremo, para que sua sensibilidade e sensatez sejam aumentadas. Nós também ouvimos a acusação de "elitismo" dos mais escolarizados e eu às vezes me pergunto como a escolaridade pode ter se tornado uma desqualificação. Bem, não podemos zombar da ignorância (como educadores, concordamos com isso), mas a ignorância deve sim ser corrigida. Como resultado, a reivindicação de que as opiniões dos mal-informados tenham o mesmo peso é absurda e perigosa. Porém, os criminosos insensíveis e os líderes autoritários são irreparáveis. Seria ingênuo de nossa parte pensar que eles pelo menos se sentariam à mesa da negociação. Existe uma estrofe na Upanishads que se encaixa bem nessa discussão, que diz mais ou menos o seguinte "Dar conselhos a um tolo obstinado é como dar leite a uma serpente que dorme, porque, depois de consumir o leite, ela vai expelir somente o veneno"14. Há um grande risco de exposição à toxicidade quando você pensa que pode dialogar com um tolo obstinado com planos diabólicos. Eu acho que isso capta bem o dilema que as pessoas de bem estão enfrentando neste clima político. Triste, mas verdadeiro.

Fink: Espera-se que entre os professores e servidores das instituições educacionais, bem como em pelo menos algumas situações corporativas, o monologismo tenha o potencial de abrir caminho para o dialogismo. Eu fiquei intrigado com a sua crítica à prática comum das instituições de usar brainstorming (p.126-8), no Capítulo 7, cujo título fala do monologismo em termos de "Diferenças como a ânsia pelo poder" e do dialogismo como "Liberdade de escolha". Com base nessa estrutura, brainstorming poderia ser uma situação dialógica por excelência. Contudo, citando um livro de Sunstein e Hastie, você afirma que o receio de punição dos membros menos poderosos por aqueles no topo da hierarquia e "a pressão social para se estar em conformidade" (p.126) tendem a arruinar a eficácia de brainstorming [tempestade de ideias] ao ponto que essa técnica se torna a

\footnotetext{
${ }^{14}$ PARAMANANDA, S. The Upanishads. Traduzido do sânscrito para o inglês e comentado por Swami Paramananda. Boston: Wilder Publications, 2011.
} 
evidência de "lavagem cerebral". Para ser justo, em algumas sessões de brainstorming nas quais eu participei, o entendimento fundamental era que o propósito (de brainstorming) não seria uma exploração aberta de possíveis objetivos, mas sim as formas mais pragmáticas de atingir certos objetivos que não estariam abertos a questionamentos, e esses diálogos eram frequentemente muito úteis. Mas se isso é dialogismo, é dialogismo leve. Como pode uma instituição - especialmente uma corporação, na qual é muito difícil alcançar além das considerações financeiras e encontrar uma posição diferente possivelmente alcançar o nível de metaconscientização e crítica ilimitadas que, na realidade, exigem o dialogismo sem restrições?

Bandlamudi: Acho curioso que você tenha lido parte do título do capítulo 7 - Diferenças como a ânsia pelo poder - como monologismo e a outra parte - Liberdade de escolha como dialogismo, porque em minha formulação trata-se de um continuum e da verdadeira essência da dialogicidade. Eu invoco a assertiva de Nietzsche - "pluralidade de interpretações, um sinal de força" ${ }^{15}$ - para argumentar que ceder o seu território e abrir espaço para o outro é na realidade um sinal de força e poder. De forma nenhuma isso diminui a estatura do self; pelo contrário, isso mostra sua confiança e disposição para permitir aos outros a disrupção dos seus padrões de pensamento. Você pode ao fim aceitar por completo os pontos de vista dos outros, ou aceitá-los parcialmente, ou rejeitá-los totalmente, mas o poder está em ouvir pontos de vista divergentes. O poder pode ser demonstrado apenas em um mundo de diferenças, enquanto um mundo homogeneizado e monológico é uma criação artificial e nesse tipo de mundo existe apenas a força bruta e não o poder confiante, que é assertivo e flexível.

Fink: Sim, quando eu disse isso, eu estava pensando na ânsia pelo poder no sentido restrito, mas você defende o argumento - corretamente, eu creio - de que existe um desejo pelo poder que beneficia os outros, bem como o self.

\footnotetext{
${ }^{15}$ NIETZSCHE, F. The Will to Power. Translated by Anthony M. Ludovici. New York: Dover Publications, 2019.
} 
Bandlamudi: Eu penso que os resultados encontrados por Sunstein e Hastie em seu livro Wiser $^{16}$ sejam convincentes e que eles reforcem minha argumentação. Eles demonstram que qualquer instituição, seja corporativa, governamental ou educacional, com uma estrutura hierárquica em que brainstorming seja somente um rótulo e a realidade seja lavagem cerebral, raramente deixa qualquer espaço para a inovação, enquanto que as instituições que são incrivelmente diversas (diversidade de ideias, não etnia), nas quais haja espaço para a dissidência, criam o tão necessário espaço para a inovação. As primeiras operam com base em fórmulas fixas e procedimentos-padrão, enquanto as últimas ousam pensar fora da caixa e então preparam um solo fértil para a criatividade. Com relação a seu ponto de vista sobre "objetivos fixos" e discutir sobre maneiras de alcançá-los, talvez se trate de um dialogismo leve (é uma definição bem generosa) de forma bastante limitada, porque a discussão é a respeito das metodologias e não sobre os postulados teóricos. Por exemplo, os gestores de instituições educacionais fazem exigências pesadas do ponto de vista avaliativo (nós conhecemos isso por dentro) e produzem métricas e modelos variados para medir o progresso dos alunos, e os educadores que têm experiência de primeira mão no contexto de sala de aula julgam esses instrumentos avaliadores como inválidos, não confiáveis e enganosos. Além disso, a escala de mensuração está muito distante da realidade. Ademais, o impacto da educação não pode ser expresso como se fosse um perfil mostrando o "antes" e o "depois" de um programa de emagrecimento. Como se pode contribuir para essa discussão quando o paradigma por si só já é falho? É como um autor que cria seu herói como um porta-voz mecânico para expressar sua visão de mundo e nunca permitir que o herói fale o que pensa. Essas obras de literatura não passam na prova do tempo e não deixam espaço para ideias concorrentes. Sunstein e Hastie salientam que as instituições que abrem as portas para o excêntrico - aquelas que desafiam as fórmulas já estabelecidas - possuem muito mais probabilidade de lançarem novos produtos no mercado (indústrias e corporações) e soluções inovadoras para problemas persistentes (governo) e avanços teóricos e filosóficos (universidades). Talvez precisemos reconfigurar os velhos conceitos de uma nova forma - o poder dialógico, a liberdade dialógica e o desenvolvimento dialógico muito mais fortes e desejáveis porque são humanos e humanistas ao mesmo tempo.

\footnotetext{
16 SUNSTEIN, C. R.; HASTIE, R. Wiser: Getting beyond Groupthink to Make Groups Smarter. Boston: Harvard Business Review Press, 2014.
} 


\section{REFERÊNCIAS}

BANDLAMUDI, L. Dialogics of Self, The Mahabharata and Culture: The History of Understanding and Understanding of History. UK: Anthem Press, 2010.

BANDLAMUDI, L. Difference, Dialogue, and Development: a Bakhtinian World. New York: Routledge, 2016.

NANDY, A. An Ambiguous Journey to the City: The Village and Other Odd Ruins of the Self in the Indian Imagination. New Delhi: Oxford University Press, 2006.

NIETZSCHE, F. The Will to Power. Translated by Anthony M. Ludovici. New York: Dover Publications, 2019.

PARAMANANDA, S. The Upanishads. Translated and commented by Swami Paramananda. Boston: Wilder Publications, 2011.

RAMANUJAN, A. K. Collected Poems. New Delhi: Oxford University Press, 1995.

RAMANUJAN, A. K. How Can One Write about Bosnia. In: Collected Poems. New Delhi: Oxford University Press, 1995, p.247.

SUNSTEIN, C. R.; HASTIE, R. Wiser: Getting beyond Groupthink to Make Groups Smarter. Boston: Harvard Business Review Press, 2014.

Recebido em 22/07/2019

Aprovado em 30/08/2019 